\title{
4-Oxoproline as a Site-Specific Infrared Probe: Application to Assess Proline Isomerization and Dimer Formation
}

\author{
Rachel M. Abaskharon ${ }^{+}$, Debopreeti Mukherjee ${ }^{+}$, and Feng Gai* \\ Department of Chemistry, University of Pennsylvania, Philadelphia, PA 19104 \\ ${ }^{+}$These authors made equal contribution
}

Supporting Information 


\section{Onsager Reaction Field Calculations}

For $1 \mathrm{M} 3 \mathrm{P}$, the Onsager reaction field associated with a specific solvent was calculated using the following equation:

$$
F_{\text {Onsager }}=\left(\frac{\mu_{0}}{a^{3}}\right)\left[\frac{2(\varepsilon-1)\left(n^{2}+2\right)}{3\left(2 \varepsilon+n^{2}\right)}\right]
$$

Here, $\mu_{0}$ is the permanent dipole moment of the solute in the gas phase, $a$ is the radius of the Onsager cavity, $\varepsilon$ is the dielectric constant of the solvent, and $n$ is the index of refraction of the solute. The $\varepsilon$ values used in this study were obtained from reference 1 . The other parameters used here are as follows: $n(1 \mathrm{M} 3 \mathrm{P})=1.451$ at $20^{\circ} \mathrm{C}$, which was obtained from the website of Sigma Aldrich, $a^{3}(1 \mathrm{M} 3 \mathrm{P})=167 \AA^{3}$ molecule $^{-1}$, which was estimated from the van der Waals volume of $1 \mathrm{M} 3 \mathrm{P}$, and $\mu_{0}(1 \mathrm{M} 3 \mathrm{P})=3.242 \mathrm{D}$, which was calculated using Gaussian calculations with B3LYP/6-31+G(d,p) as the basis set.

(1) Riddick, J. A.; Bunger, W. B.; Sakano, T. K. Organic Solvents: Physical Properties and Methods of Purification. Fourth Edition. John Wiley and Sons, New York, NY, 1986.

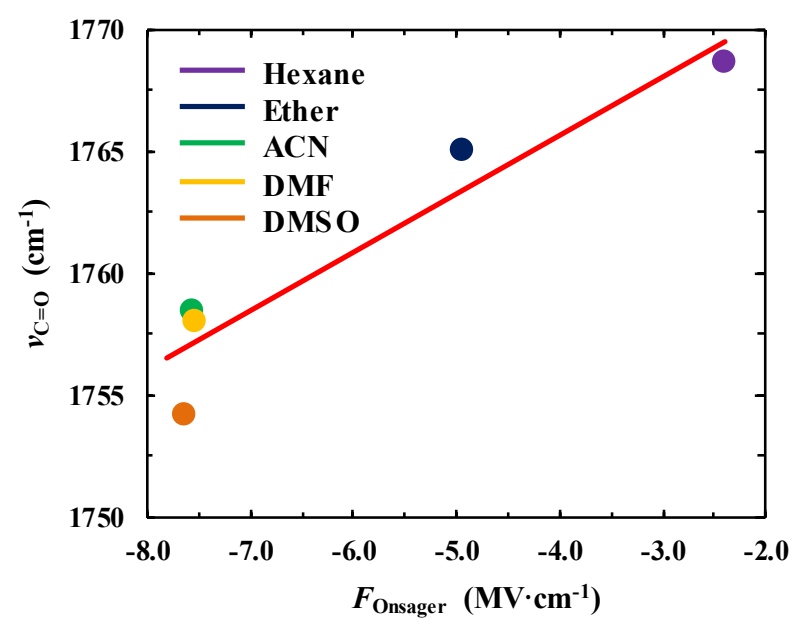

Figure S1. The $\mathrm{C}=\mathrm{O}$ stretching frequency of $1 \mathrm{M} 3 \mathrm{P}$ versus the Onsager reaction field of the solvent, as indicated. A linear fit of the data yields $v_{\mathrm{C}=\mathrm{O}}\left(\mathrm{cm}^{-1}\right)=2.38 F_{\text {Onsager }}+1775.1$. 

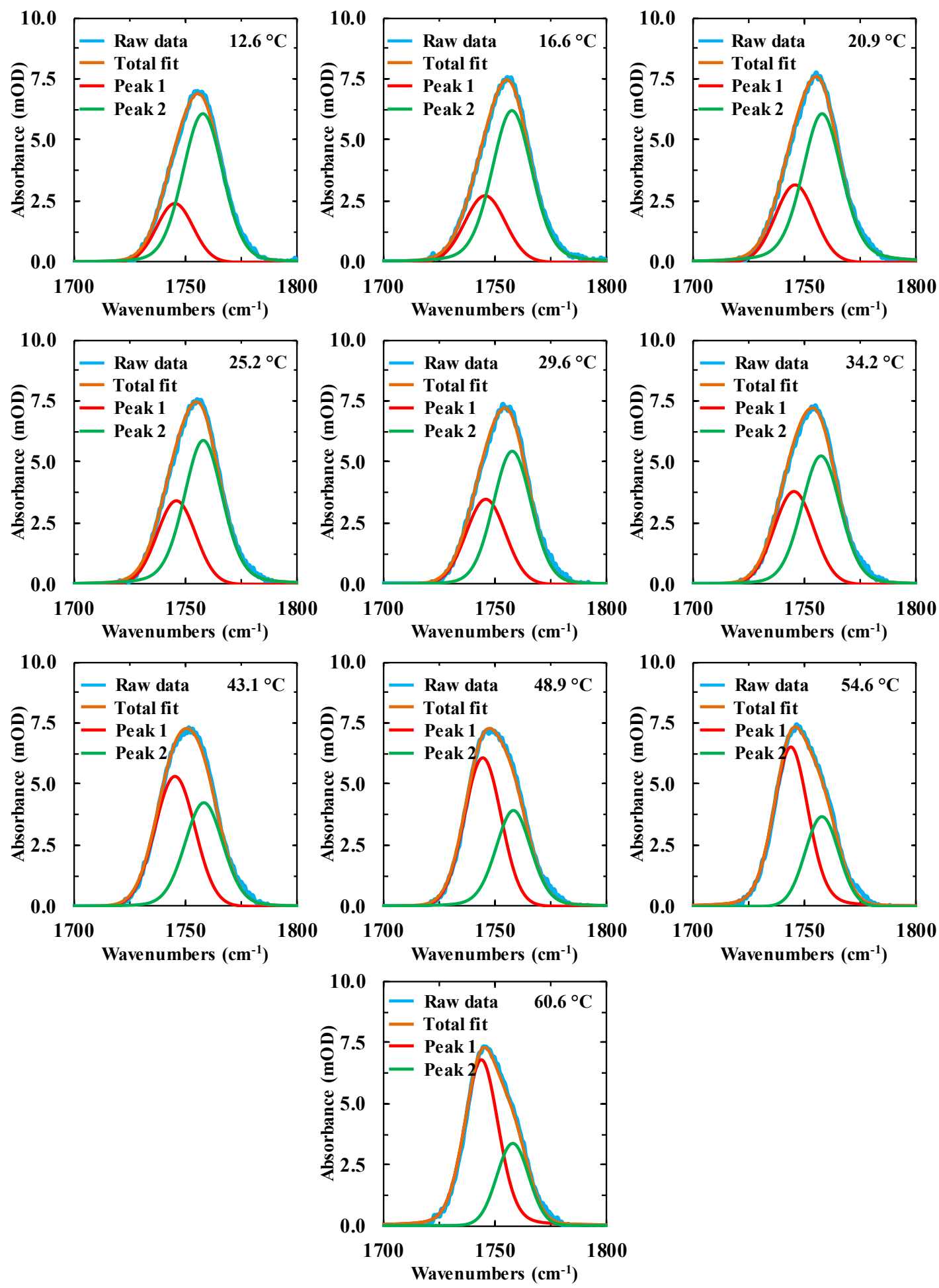

Figure S2. Pseudo-Voigt fits of the $\mathrm{C}=\mathrm{O}$ stretching bands of $\mathrm{KP}_{\mathrm{ox}} \mathrm{G}$ in $\mathrm{D}_{2} \mathrm{O}(\mathrm{pH}$ 7.0) at different temperatures, as indicated. In comparison to the original spectra in Figure 5, a background arising from the amide I' band in each case has been subtracted. 


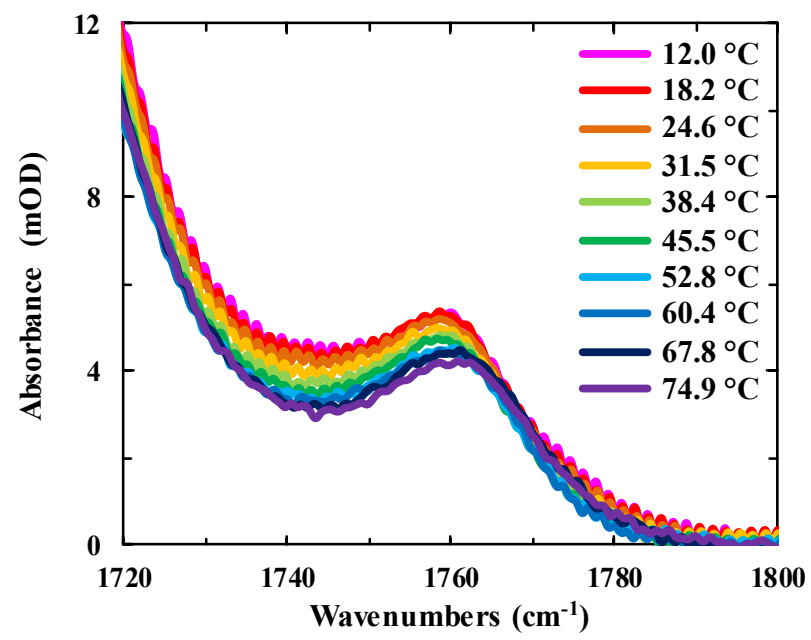

Figure S3. Temperature dependence of the $\mathrm{C}=\mathrm{O}$ stretching bands of $\mathrm{GP}_{\mathrm{ox}} \mathrm{G}$ in $\mathrm{D}_{2} \mathrm{O}(\mathrm{pH}$ 7.0).
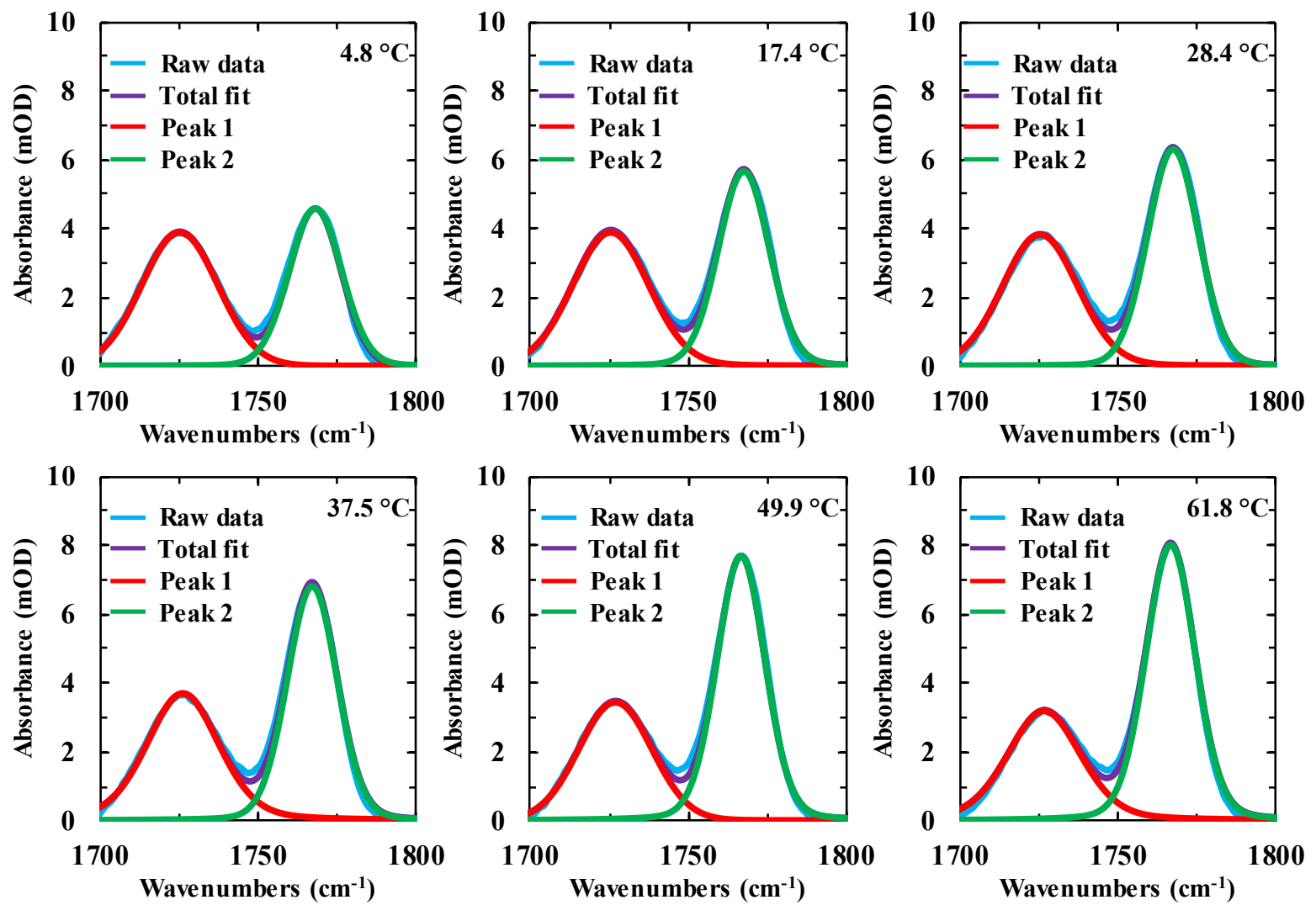

Figure S4. Pseudo-Voigt fits of the $\mathrm{C}=\mathrm{O}$ stretching bands of $\mathrm{P}_{\mathrm{ox}}$ in $2.0 \mathrm{M}$ proline solution $(\mathrm{pH}$ $4.0)$ at different temperatures, as indicated. 